\title{
Interpersonal Interactions in Engineering Teams: Findings from a Multi-Year Mixed Methods Study at Three Institutions
}

\section{Mr. Héctor Enrique Rodríguez-Simmonds, Purdue Engineering Education}

Raised in South Florida, born in Mexico. Half Colombian and half Mexican; proud Mexilombian. Héctor acquired an MS in Computer Engineering and is a $\mathrm{PhD}$ candidate in Engineering Education, both at Purdue University. His research interests are investigating the experiences of LGBTQ+ students in engineering and tapping into critical methodologies and methods for conducting and analyzing research.

Tara C. Langus, University of Nevada, Reno

Tara C. Langus is a Ph.D. student pursuing her degree in STEM Education at the University of Nevada, Reno. Her research interests include the integration of socioscientific and sociopolitical issues in the college STEM classroom and increasing the representation and retention of underrepresented minorities in STEM. Prior to graduate school, she completed Bachelor's and Master's degrees in Biology in which she studied insect immunology and chemical ecology.

Mr. Nelson S Pearson, University of Nevada, Reno

Nelson Pearson is an Ph.D. student at the University of Nevada, Reno. His research interest includes, social networks and the integration of diverse populations, engineering culture as well as engineering pedagogy. His education includes a B.S. and M.S. in Civil Engineering from the University of Nevada, Reno.

\section{Mr. Justin Charles Major, Purdue University-Main Campus, West Lafayette (College of Engineering)}

Justin C. Major is a fourth-year Ph.D Candidate and National Science Foundation Graduate Research Fellow in the Purdue University Engineering Education Program. As an undergraduate student at the University of Nevada, Reno (UNR), Justin completed Bachelor's degrees in both Mechanical Engineering and Secondary Mathematics Education with an informal emphasis in engineering education. Through his involvement in the UNR PRiDE Research Lab and engagement with the UNR and Northern Nevada STEM Education communities, he studied student motivation, active learning, and diversity; developed K-12 engineering education curriculum; and advocated for socioeconomically just access to STEM education. As a Ph.D. Candidate with the STRiDE Research Lab at Purdue University, Justin's dissertation research focuses on the study of Intersectionality Theory and the intersectionality of socioeconomic inequality in engineering education, use of critical quantitative methodology and narrative inquiry to understand the complex stories of engineering students from traditionally minoritized backgrounds, and the pursuit of a socioeconomically just engineering education.

\section{Dr. Adam Kirn, University of Nevada, Reno}

Adam Kirn is an Assistant Professor of Engineering Education at University of Nevada, Reno. His research focuses on the interactions between engineering cultures, student motivation, and their learning experiences. His projects involve the study of student perceptions, beliefs and attitudes towards becoming engineers, their problem solving processes, and cultural fit. His education includes a B.S. in Biomedical Engineering from Rose-Hulman Institute of Technology, a M.S. in Bioengineering and Ph.D. in Engineering and Science Education from Clemson University.

\section{Dr. Allison Godwin, Purdue University at West Lafayette}

Allison Godwin, Ph.D. is an Assistant Professor of Engineering Education at Purdue University. Her research focuses what factors influence diverse students to choose engineering and stay in engineering through their careers and how different experiences within the practice and culture of engineering foster or hinder belongingness and identity development. Dr. Godwin graduated from Clemson University with a B.S. in Chemical Engineering and Ph.D. in Engineering and Science Education. Her research 
earned her a National Science Foundation CAREER Award focused on characterizing latent diversity, which includes diverse attitudes, mindsets, and approaches to learning, to understand engineering students' identity development. She has won several awards for her research including the 2016 American Society of Engineering Education Educational Research and Methods Division Best Paper Award and the 2018 Benjamin J. Dasher Best Paper Award for the IEEE Frontiers in Education Conference. She has also been recognized for the synergy of research and teaching as an invited participant of the 2016 National Academy of Engineering Frontiers of Engineering Education Symposium and the Purdue University 2018 recipient of School of Engineering Education Award for Excellence in Undergraduate Teaching and the 2018 College of Engineering Exceptional Early Career Teaching Award. 


\section{Interpersonal Interactions in Engineering Teams: Findings from a Multi-Year Mixed Methods Study at Three Institutions}

\section{Introduction}

A key learning outcome in engineering is the ability to work in collaborative and inclusive teams. As engineering becomes a global endeavor, this outcome gains increasing importance to undergraduate engineering education. When it comes to working in teams in this global environment, research shows positive and negative findings for students working in diverse teams (i.e., race/ethnicity, gender, sexual orientation, disability status). Positive findings include increased divergent thinking, idea generation, higher quality products, and increased productivity [1]-[3]. Negative findings highlight sustained conflict in teams, decreased affect, and increased frustration [4], [5]. To understand these mixed findings, research has examined the role faculty have in shaping students' attitudes about diversity and teaming [6]. However, there have been few systematic studies of how student team formation and students' experiences in diverse teams influence students' attitudes and beliefs about diversity and teaming as well as outcomes of those teaming experiences to promote inclusion in the engineering classroom.

Research on teaming experiences in engineering has often focused on the ways in which teams can generate high-quality solutions to complex problems [7]-[11]. In engineering, the Comprehensive Assessment of Team-Member Effectiveness (CATME) tool has emerged as the leading mechanism for assessing student effectiveness during each phase of student development [8], [10]. While these models reflect best practices in team development and consider ways to create diverse teams that support underrepresented students, they have not adjusted their practices to measure the ways students are or are not making engineering environments more inclusive. This focus is especially vital as ABET has made explicit changes to its criteria that make creating an inclusive teaming environment an essential skill for engineers [12]. In response to these calls for change, research has begun to understand how engineering teaming experiences can be more inclusive [13]-[22].

Adding to this literature, our research examines how students interact in diverse teams to provide better support for building students' inclusive and collaborative teaming competencies. This multiphase mixed-methods study was conducted in three different university contexts: a large Midwestern land-grant research-intensive university (CentralU), a large Western land-grant institution (WestU), and an East Coast small private religiously affiliated school that has been recognized for its efforts in working to create an inclusive environment (EastU). In this project, we are working to answer the following research questions:

Research Question 1) What changes occur in students' diversity sensitivity, multicultural effectiveness, and engineering practices as a result of working in diverse teams?

Research Question 2) How do students' perceptions of diversity, attitudes, and engineering practices change when they work on diverse teams? This paper will 
focus on emergent findings regarding how students create team norms for inclusion.

\section{Theoretical Framing}

In our research, we found Tuckman's [23] revised theory of the five stages of teaming useful in determining how students interacted in a team. The five stages are Forming, Storming, Norming, Performing, and Adjourning, and these stages provide a simple way to understand the process in which teams come together and function. The Forming stage consists of team members creating ground rules, testing one another's boundaries, and the beginning of norms being established [24]. In this stage, team member's past experiences in teams also influence their formation [25]. Storming is characterized by a lack of unity around interpersonal issues and resistance to interpersonal relationships to maintain psychological security, rather than focusing on the task at hand. During the Norming stage, the team becomes more cohesive. In this stage, team member roles have been established. The team is focused on finding efficient ways of working together using their shared mental models [24]. The Performing stage is characterized by functioning like a well-oiled machine; the team is task-focused, with fluid roles naturally switching between team members. Group relationships are maintained to reach a shared goal. Conflicts, if they occur, are healthy, and interactions can be jovial and humorous. The last stage is Adjourning. This stage is comprised of end-of-project task completion with a potential for feelings of loss at the conclusion of the project [25].

While each of these stages is important in teaming function and development, the Norming phase was most important in our work to understand how students interacted within the team in subsequent stages and also affected how students operationalized inclusion in their teams. Prior research indicates that highly cohesive teams develop strong norms to which group members adhere [26]. In a review of teaming literature, psychologists Johnson and Johnson [27] identified three clusters of teaming dynamics: cognitive process variables (i.e., quality of learning), social variables (i.e., mutual support among group members), and instructional variables (i.e., type of task). While each of these aspects is important in teaming, social variables shaped by student socialization and norming are linked to inclusive or exclusive environments.

\section{Methods}

\section{Study Sites}

The three sites at which we conducted our research are geographically different and vary in terms of the student body, international and domestic students, as well as the type and amount of diversity-related instruction in their first-year engineering classes. The form and type of messaging the universities use to communicate regarding diversity, equity, and inclusion varies. CentralU is a large research-intensive university. This university has many international students and offers first-year students one class period dedicated to discussing issues of diversity and inclusion. At the time of the study, WestU had recently updated course materials to reflect best practices for inclusive engineering teams. 
Additionally, students received approximately three hours of direct instruction on evidence-based teaming practices. EastU in this study is a small religiously-affiliated institution on the East Coast, whose engineering program is developed on a core value of inclusivity. The new engineering program communicates messages of diversity through posters in the halls and inclusive policies. For example, we observed purposefully placed posters of women and people of color in STEM throughout hallways and faculty offices frequented by students.

\section{Data Streams and Analysis}

For this mixed-methods study, we utilized electronic surveys, interviews, and focus groups to collect information on engineering students' attitudes, beliefs, and perceptions of diversity, sense of belonging, and reported and observed interactions in teams. Simultaneously we collected information on students' social networks as a proxy for the inclusiveness of the social structures occurring in first-year engineering design courses. We conducted ANOVA and Kruskal-Wallis testing to determine if students' demographic identifiers significantly affected their first-year engineering experiences (e.g., sense of belonging, social activity, engineering identity development) [19], [28], [29].

We chose to interview students in teams with varying levels of diversity by a matrix of factors (i.e., gender identity, race/ethnicity, international student status, and disability status). We also interviewed students who had large shifts in their attitudes about teaming and diversity or belonging during the semester. We interviewed a total of 36 students. Interviews and survey collection transpired from 2016-2019 across three different sites. At the first two sites, we conducted two 60-90 minute semi-structured interviews with each participant. The first interview protocol delved into students' backgrounds, beliefs, and approaches to teaming. The second interview protocol focused on particular teaming experiences and interpersonal interactions occurring in their first-year engineering course. All students chose or were given pseudonyms. Interviews were examined using both Interpretative Phenomenological Analysis (IPA) [30], [31] and Directed Content Analysis (DCA) [32], [33]. At the third site, interviews were 30 to 60 minutes and focused on social networks, teaming experiences, perceptions of diversity while working on teams, and inclusionary actions while working on teams.

Finally, we conducted ethnographic observations of specific student teams at the first two institutions (i.e., CentralU, WestU). These observations recorded students' interactions in the classroom while working on engineering design tasks. Through these observations, we were able to see how students interacted with one another and discussed engineering design. We used student observations to triangulate findings from the quantitative results and in-depth qualitative interviews.

\section{Overview of Findings}

Overall, our results indicate that over their first-semester, first-year engineering course students norm to the cultural practices modeled by others and by instructors, and engineering students come into engineering degree programs with high levels of belonging. At CentralU, we observed that students needed guidance during the team norming phase for them to enact more inclusive teaming practices. For example, getting to know each other beyond visible differences, 
facilitating deeper socialization in and out of classroom time, increasing team trust, and allowing greater role selection in teaming tasks. At the WestU, we found that belonging is high for first-year engineering students and is associated with finishing engineering projects. While belonging is high for all students, in general, we found instances of exclusionary practices in teams. Our findings indicate that inclusion must be studied beyond simple self-report or surface-level interview protocols.

Results at EastU show even with systematic and overt messages about inclusion in engineering, students still need support to develop inclusive practices within teams. Across the three sites, institutional efforts do not always translate into students enacting inclusive teaming practices. For example, classroom-level and university-level belonging were high and correlated with each other but did not translate to specific actions in teaming environments. We discuss our findings from this larger study in detail below and provide suggestions for creating inclusive teaming environments across institutional contexts.

\section{Differences in Institutional Contexts}

Across all three institutions, participants discussed the necessity and utility of teamwork in engineering. In our previous work, we described how teams with low socialization [19] focus on the completion of tasks and prioritize technical aspects of engineering over social aspects of engineering problem solving, leading to a lack of more profound norming practices. Across the institutions, participants discussed that diversity was important to produce better solutions and complete complex engineering tasks more efficiently. Participants also discussed how the methods by which they completed the task were not important. Their focus was on completing the task successfully.

Participant's enactments of the storming and norming stages differed. For example, one all-male team at CentralU normed around getting a good grade in the class and producing high-quality work, less about getting to know their teammates. This team did not spend much time testing each other's boundaries or grappling with interpersonal differences. They leaned on their shared interests such as sports and music as well as their all-male gender to feel like they knew one another. They felt their same gender made working together "laid back," and more straightforward as Stanley shared: "just because I feel like we knew better what each member wanted to do and also it was very easy to tell the work habits I guess of each group or each team member." Given their similarities, this team felt they had socialized sufficiently to get work done.

However, Ezekiel, one member of the team, felt antsy because his team lacked diversity and did not socialize. While the result for his team was that a good grade was acquired in the class, his teaming experience was lacking in that he did not get to interact with diverse people and postponed learning class material. Ezekiel was also more concerned with seeming like a well-performing teammate: meeting the team's objectives rather than learning the material with his team. He stated: "I'm going to figure out how to do this on my own at some later point so I'm doing well with the practical. For now, we need to get the good grade, so let's figure out how we're going to get that." While team roles were established in the forming and storming stages of teaming, the established roles did not rotate as often in this team. 
Another team did not have a salient identity (such as gender) over which to bond easily. This team valued getting to know team members at a deeper level. The lack of a clearly evident shared identity along with an appreciation for getting to know team members more holistically helped this team collaborate more intimately, helped them understand their fellow teammates better, and fostered a more inclusive teaming environment. Mari shared:

"We'd be like, 'Let's start working at 6:00.' Everyone would get hungry 20 minutes in. We'd go eat, we'd come back. Being forced to have conversation. It's not like we were, "Oh, we have to sit together." Well, we went to dinner at the same place, we all know each other [...] We would sit together, and when you sit with someone you talk to them. It just happened."

Their increased intimacy overall made their diverse teaming experience better, albeit with added frustration at times. Sarah shared: "I think we were a well-rounded team. We agreed and disagreed, but we always found a way to agree eventually." This team had less of an individualistic, divide-and-conquer workstyle, and collaborated more closely and harmoniously with one another. The depth of interaction translated to more inclusive behaviors by some members, such as learning work strategies from one another and arguing less about approaches to solving problems.

In other teams, the added intimacy led to less professionalism. Mallory (from WestU) described this interaction:

People started getting lazy [...] towards the end. I think that's why we weren't working as well together because we'd just gotten so used to, it was like working with people that you already know so you know how they're going to react, so you just don't care as much.

Still, other students like Bay (EastU) described bonding with her teammates on a deeper level, likening this familiarity and reliability to that of close friends:

I really think I've made some new friends that are easily able to help. Everyone in my team, doesn't matter what time I text them, they're able to text me back and try to be responsive as they can. So I think that's very helpful and beneficial to succeeding in engineering.

At EastU, students hesitated to discuss what they perceived as controversial topics around diversity or politics. Individuals believed that diversity was important. Students felt conversations around diversity needed to happen. However, they should not just "happen" in all engineering spaces because of the negative way in which people react. Johannes, a student and teaching assistant at EastU, felt the "smaller community" of EastU was almost like a "bubble." He was "further pushed away from my [political] thoughts since I got here because being in engineering school, I'm constantly busy, so I don't watch TV anymore." While Johannes saw the importance of discussing topics of diversity and politics in engineering, he also noted his 
engineering peers at EastU often reacted negatively to these conversations or felt they did not belong in engineering. He believed they reacted negatively because they had limited viewpoints and vocabulary. The norms of socialization at EastU, as well as scarcity of time, channeled students to focus on tasks, jumping to the fourth teaming phase: performing, rather than spending time developing interpersonal teammate knowledge (part of the second and third phases: storming and norming). Johannes felt it was important to know teammates "so you can understand, and you can pull in all these different experiences that will go in towards that [product] that you're working on that's going to make it so great."

In summary, teaming in engineering is a complex topic. Our research shows that merely placing students in diverse teams does not automatically translate into inclusive teams. Students pull from their previous teaming experiences, institutional context, and their understanding of the purpose of engineering teams as they form, storm, norm, and perform. While getting to know each other better can lead to increased frustration between team members, a place in which to have difficult interpersonal conversations can lead to a more intimate understanding of one another, leading to more welcoming, collaborative, and understanding engineering teams. For example, in our study, teams that more intimately knew one another manifested increased role-switching behaviors, leading to increased skill sharing and learning from one another. The increased intimacy led to a more collaborative working environment where "everyone feels welcome, everyone is listened to, everyone does something that they enjoy doing, not just what they're good at." [Mari]

\section{Discussion and Conclusions}

Engineering shapes and is shaped by students' attitudes and beliefs about the importance and role of diversity and inclusion. Historically, the field has been characterized by a lack of representation and is predominantly White, male, and able-bodied [34], [35]. Engineering has also often ignored non-technical foci in courses and downplayed the importance of social context [36], [37]. Together, these norms create contexts in which students do not see engineering as related to issues of diversity and inclusion. Therefore, they may not be motivated to discuss or enact these topics in their classrooms or teams [38], [39]. We found similar trends in our work - students who valued and were motivated to act inclusively deeply socialized with their teammates. These students asked questions and learned about teammates beyond visible differences and engineering task-related skills. These socialization practices led to team norms that valued differences and supported inclusive practices during team interactions. Some of this behavior can be shaped by the institutional structures and norms and can provide leverage points for supporting more inclusive practices in engineering teams.

The results of this multi-year project indicate the need to continue to develop curricula to support students' understanding of diversity and inclusion within engineering classrooms as well as provide structured instruction on how to engage inclusive behaviors in teams. Often, students are placed into teams (sometimes intentionally based on evidence-based practices and other times randomly) with less effort spent on scaffolding challenging conversations about diversity with students in these teams. However, the process of forming teams is not the only consideration in 
promoting teams that are effective. Effectiveness must move beyond "getting the good grade" and focus on providing experiences that support all students within teaming contexts.

\section{Future Work}

The results of our work have indicated that socialization processes are vital in helping students create more inclusive first-year engineering teams. However, our work has also shown that navigating the storming and norming processes of team formation is highly variable. Future work should examine how engineering educators and students can better direct or guide teaming experiences to create inclusion. Further, the socialization processes described by students that led to inclusion reflects a level of privilege. Students had the time and money to be able to meet outside of course hours in informal environments such as dining halls. Many students do not have the privilege to meet in these ways due to their current socioeconomic status or due to commitments outside school such as work and family. Given these realities of students, we must examine ways that we can make positive socialization processes for inclusion equitable to all students in engineering.

\section{References}

[1] C. J. Nemeth, "Dissent as driving cognition, attitudes, and judgments," Social Cognition, vol. 13, no. 3, pp. 273-291, Sep. 1995.

[2] P. L. McLeod, S.A. Lobel, and T.H. Cox Jr, "Ethnic diversity and creativity in small groups," Small Group Research, vol. 27, no. 2, pp. 248-264, May 1995.

[3] R. Guimera, B. Uzzi, J. Spiro, and L. A. N. Amaral, "Team assembly mechanisms determine collaboration network structure and team performance," Science, vol. 308 no. 5722, pp. 697-702, Apr. 2005.

[4] D. A. Harrison, K. H. Price, and M. P. Bell, "Beyond relational demography: Time and the effects of surface-and deep-level diversity on work group cohesion," Academy of Management Journal, vol. 41, no. 1, pp. 96-107, Feb. 1998.

[5] B. Mazur, B. Mazur, and P. Biatosticka, "Cultural diversity in organisational theory and practice," Journal of Intercultural Management., vol. 2, no. 2, pp. 5-15, 2010.

[6] K. J. Cross and S. L. Cutler, "Engineering faculty perceptions of diversity in the classroom." In ASEE Annual Conference and Exposition, Conference Proceedings (Vol. 2017).

[7] M. L. Loughry, M.W. Ohland, and D. J. Woehr, D. J., "Assessing Teamwork Skills for Assurance of Learning Using CATME Team Tools," Journal of Marketing Education, 36(1), 5-19, 2014. 
[8] M. L. Loughry, M. W. Ohland, and D. DeWayne Moore "Development of a Theory-Based Assessment of Team Member Effectiveness," Educational and Psychological Measurement, 67(3), pp. 505-524, 2007

[9] M. Murray, G. Hendry, G., and R. McQuade, "Civil Engineering 4 Real (CE4R): co-curricular learning for undergraduates." European Journal of Engineering Education, $1-23,2019$.

[10] M.W. Ohland, M. L. Loughry, D. J. Woehr, L. G. Bullard, R. M. Felder, C. J. Finelli, R. A. Layton, Hal R. Pomeranz, and Douglas G. Schmucker. "The comprehensive assessment of team member effectiveness: Development of a behaviorally anchored rating scale for self-and peer evaluation." Academy of Management Learning \& Education 11, no. 4 pp. 609-630, 2012.

[11] S.P. Schaffer et al., "Self-Efficacy for Cross-Disciplinary Learning in Project-Based Teams," Journal of Engineering Education, 101(1), 82-94, 2012.

[12] ABET, "Accreditation Changes," abet.org, 2019. [Online] Available: https://www.abet.org/accreditation/accreditation-criteria/accreditation-changes/. [Accessed: June 27, 2019].

[13] K. J. Cross, "The Experiences of African-American Males on Multiracial Student Teams in Engineering," PhD. thesis, Virginia Tech, Blacksburg, VA, 2005.

[14] K. J. Cross, and M. C. Paretti, "Identification with academics and multiple identities: combining theoretical frameworks to better understand the experiences of minority engineering students," In Proc. 119th ASEE Annual Conference and Exposition, 2012.

[15] K. J. Cross, and M. C. Paretti, "The impact of personal interactions on the experience of African-American males on multiracial student teams," In Proc. 2015 ASEE Annual Conference and Exposition, 2015.

[16] A. Godwin, A. Kirn, J. Rohde, "Awareness without action: Student attitudes after engineering teaming experiences," International Journal of Engineering Education, 36(6A), pp. 1878-1891, 2017.

[17] A. Kirn, et al., "Building Supports for Diversity through Engineering Teams," 2012 American Society for Engineering Education Annual Conference and Proceedings, 2012.

[18] T. Langus, N. Pearson, J. Major, A. Godwin, and A. Kirn, "Work in Progress: How Traumatic Events Help Shape Social Exclusion in Engineering Teams," American Society for Engineering Education Annual Conference, 2019.

[19] N. Pearson, H. E. Rodríguez-Simmonds, T. Langus, A. Godwin, and A. Kirn, "Understanding How First-Year Engineering Students Create Effective, Collaborative, 
and Inclusive Teams," American Society for Engineering Education Annual Conference, 2019.

[20] N. S. Pearson, J. C. Major, A. Godwin, A. Kirn, "Using Social Network Analysis to Study the Social Structures of Inclusion," American Society for Engineering Education Annual Conference, 2018.

[21] H. E. Rodríguez-Simmonds et al. (2017). Forget Diversity, Our Project is Due. American Society for Engineering Education Annual Conference and Proceedings. American Society for Engineering Education Annual Conference, Columbus, Ohio.

[22] H. E. Rodríguez-Simmonds, N. S. Pearson, B. P. Jackson, T. C. Langus, J. C. Major, A. Kirn, and A. Godwin, "Board 124: Interpersonal Interactions that Foster Inclusion: Building Supports for Diversity in Engineering Teams." 2018 ASEE Annual Conference \& Exposition, 2018.

[23] B. W. Tuckman and M. A. Jensen, "Stages of small-group development revisited," Group and Organization Studies 2, no. 4: 419-27, 1977.

[24] D. A. Bonebright, "40 years of storming: a historical review of Tuckman's model of small group development," Human Resource Development International, 13(1), 111-120, 2010.

[25] “Tuckman: Forming, Storming, Norming, Performing model," in BusinessBalls.com, [online document], 2019. Available: https:/www.businessballs.com/team-management/ tuckman-forming-storming-norming-performing-model/ [Accessed: January 24, 2020].

[26] S. M. Gully, D. J. Devine, and D. J. Whitney, "A meta-analysis of cohesion and performance: Effects of level of analysis and task interdependence," Small Group Research, 26, 497-520, 1995.

[27] D. W. Johnson, and R. Johnson, "The internal dynamics of cooperative learning groups", in Learning to Cooperate, Cooperating to Learn, R. Slavin, S. Sharan, S. Kagan, R. Hertz-Lazarowitz, C. Webb and R. Schmuck, Eds. 103-24, New York: Plenum Press, 1985

[28] T. Fernandez et al., "More Comprehensive and Inclusive Approaches to Demographic Data Collection,” 2016 ASEE Annual Conference \& Exposition Proceedings, 2016.

[29] A. Godwin, A. Kirn, and J. Rohde, "Awareness without action: Student attitudes after engineering teaming experiences," International Journal of Engineering Education, 36(6A), pp. 1878-1891, 2017.

[30] A. Kirn and L. Benson, "Engineering Students' Perception of the Future: Implications for Student Performance," Journal of Engineering Education, 1-51, 2018. 
[31] JA Smith, P. Flowers, and M. Larkin, Interpretative phenomenological analysis: Theory, method and research, London: Sage, 2009.

[32] H. F. Hsieh and S. E. Shannon, "Three approaches to qualitative content analysis," Qualitative Health Research, 15(9), pp. 1277-1288, 2005.

[33] P. Mayring. "Qualitative content analysis," Forum: Qualitative Social Research, 1(2), June, 2000.

[34] B. L. Yoder, "Engineering by the Numbers." 2012 American Society for Engineering Education Conference, 2012.

[35] A. L. Pawley, "Shifting the "default": The case for making diversity the expected condition for engineering education and making whiteness and maleness visible," Journal of Engineering Education, 106(4), 531-533, 2017.

[36] E. Godfrey, and L. Parker, "Mapping the cultural landscape in engineering education," Journal of Engineering Education, 99(1), 5-22, 2010.

[37] E.A. Cech and H.M. Sherick, "Depoliticization and the structure of engineering education," International Perspectives on Engineering Education, pp. 203-216, 2015. Springer, Cham, 2015.

[38] S. A. Williams, B. Lutz, C. Hampton, H.M. Matusovich, and W. C. Lee, "Exploring student motivation towards diversity education in engineering." 2016 IEEE Frontiers in Education (FIE) Conference pp. 1-5, IEEE, 2016.

[39] A. Godwin, A. Kirn, and J. A. Rohde, "Awareness Without Action: student attitudes towardteam diversity after engineering teaming experiences," The International journal of engineering education, 33(6), 1878-1891, 2017. 